Hegel fala de Antígona sem nomeá-la, deixando a peça de Sófocles como segundo plano, pano de fundo, inspiração para a reflexão filosófica sobre o mundo ético. Na parte VI da Fenomenologia do espírito, como já no final da parte V, é de Antígona, que se trata: "A ação ética: a lei humana e a lei

\section{A PROPÓSITO DE ANTÍGONA}

SUZANA ALBORNOZ

mo palavra com receio, não só porque a palavra em geral me suscita eceio, risco de mal-entendido que há em toda comunicação, mas porque receio, pelo risco de mal também consciência do risco que já foi dito muito nesta mesa-redonda. Tenho tambermo resultado de um trabaé fazer uma comunicação que não se apresenta como resultado de um trabaTho já feito mas como sugestão para exploração futura, indicação para um tratho já feito balho ainda por fazer, em aberto, un de Antígona mais uma vez é um risco. Ançada. Receio também porque falar de Antígona mais uma vez é um risco. Antígona é perigosa.

Falar de Antígona é como entrar num rio de palavras que já corre há 2.400 anos. De Aristóteles a Lacan, músicos e poetas cantaram Antígona, redisseram Antígona. Inúmeros filósofos pensaram Antígona. interpretaram

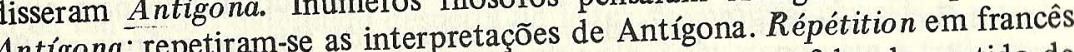
Antigona; repetiram-se as interpretaçoes de Antigona. Répétition em frances é ensaio teatral. Interpretação é a mesma palavra para se falar do sentido de algo (ou de alguém) como do encarnar, pôr em vida um personagem. Falar de Antígona é repetiç̃̃o. Também como ensaio teatral, como interpretação no Antigona é repetição. Tambem é um mito, a repetição lhe é própria. $\mathrm{O}$ ritual sentido do ensaio. Se Antigona é um mito, a to do mito se repete, se mantem com sentido enquanto se ocupar de Antígona, de Hoelderlin, Kierkegaard sentiram a necessidade de que ainda falar de Antí redizer e refazer o sentido desta filha de Edipo. Por que ainda falar de Ant en? Por que correr o risco de acrescentar uma palavra no imenso rio de gona? Por que corrígona considerada como invenção de Sófocles, puro per 2.400 anos? Seja Antígona considerada um autor dramático; seja Antígona sonagem fruto da imaginação criativa de um autor dramatico, se teria inspira uma pessoa histórica; seja considerada como um mito grego que teria inspira

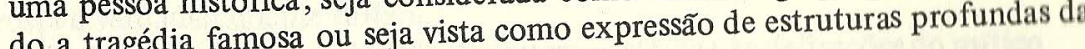
psychè humana, por que ainda falar de A.?

psychè humana, por que ainda falar de A.?

O tema deste seminário é "a presença da mulher na literatura guirmos o conceito de crítica que a entende como estudo da genese de un guire compreendermos de modo crítico a presença das mulhere

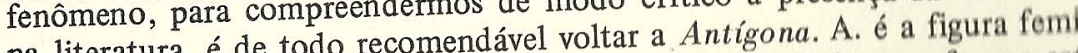
na literatura, é de todo recomendavel voltar a Antigona. Á tentar fazer a erí nina que está na origem da literatura ocidental. Rev

tica da presença da mulher na literatura ocidental.

O que dizer de Antígona? O que lembrar do que já foi dito sobre A. Dentro dos estritos limites de tempo e proposito desta comuma frase menoß co apenas recordar uma interpretação famosa e destacar uma frase menos co nhecida. Trago alguns ecos da interpretação que Hegel faz de Antigona e pre nhecida. Trago alguns ecos da inter a novas pesquisas uma frase de Ernst Bloel tendo sugerir como inspiração a novas pesquisas uma usa Antígona para interpretaçấo do feminismo contemporâneo.

Suzana Albornoz do doutoranda em Filosofia pela Eeole des Hautea fuden en Seleneen Socieles, Paris. divina, o homem e a mulher". As reflexões hegelianas, de apresentação extremamente complexas e na aparência abstratas, são na verdade um comentário do drama de Antígona. (Muitas vezes a maior dificuldade para termos acesso ao sentido de uma página filosófica, é não saber o poema que a inspira, que tramita por trás dela. Os filósofos às vezes o que fazem é transpor para a linguagem "abstrata" um trecho concreto de literatura. Comentam os poetas.) 1 preciso ter em mente a peça de Sófocles para entender a lição magistral de Ilegel. Aqui só pretendo veicular ecos da interpretação de Hegel, ecos porque através de seus intérpretes. Refiro-me a versóes de Jean-Luc Seylaz e de George Steiner. O primeiro apresenta a tradução de André Bonnard da Antífona para o francês. O segundo faz o inventário possível, embora declare impossivel o inventário dos trabalhos inumeráveis sobre A.

Segundo Jean-Luc Seylaz, para Hegel a tragédia se caracteriza por um confilio de valores. Além de encarnar valores, os heróis trágicos são caracteres sininilares, individuos com uma personalidade, prisioneiros de uma obsessão. Aliim, Creonte representa a religião do Estado mas também é um príncipe inHejure. Antígona representa as leis da família, a devoção à justiça dos mortos, Ail lill nilo escritas, mas é também uma jovem obsessionada. A tragédia nasce Hênel da existência de valores incompatíveis que do movimento ("humano, Hemaisiado humano") de obsessão e intolerância irracionais.

Creonte e Antígona têm razão. Creonte e Antígona têm suas razões.

f feonte antigona servem seus deuses. A tragédia reside na intolerância da Hiliă日 do outro. Na intolerância reside o trágico.

Dite de outro modo (ainda Hegel, segundo George Steiner) "Antígona a (iva 0 lesredo da atualidade permanente de Antígona é o de ser uma con-

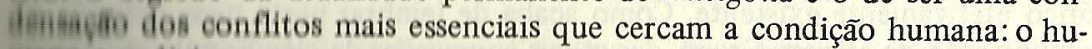
Hihing $\mathrm{e}$ o divino, os mortais e os imortais, o homem e a mulher, o velho e o Livili a flatado e a familia, a sociedade e o indivíduo, a vida e a morte, if hilf chaturais a ordem política. Os deuses do Hades e os deuses do Olim19 ( (inire Apolo e Dionisio... ).

Ciegree Steiner acrescenta que, além do "caráter conflitivo" da tragédia,

Iiin (1) Anitigona desenvolvem um diálogo de surdos. E Antígona sugere II

th inemingletude, riseo, finitude. Porque da peça de Sófocles é possível deat It lehe de que a açน̃o é que leva à destruição.

finili Bloeli, a propósito de Antígona, nos dá uma nova pista, espécie | yini feinicrpreiaglo de Antigona, Bloch sugere - por uma expressão usa(iii uini hase de Thinedpio esperança - uma utilização da reflexão sobre (xini tia interpretaçâo di história contemporânea; Antigona como recur-

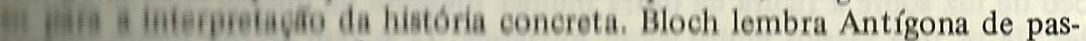

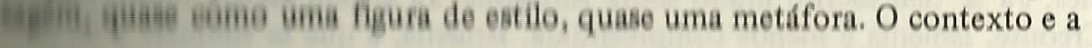


frase sugerem nova reflexão. A frase surge no contexto da análise das utopias socia Bloch chama "utopias de grupo burguesas". O sociais do seculo XX, do movimento moderno de feminismo é então pensado ao lado do sionismo e do monimento me juventude.

Para Bloch, o feminismo aparece como uma "utopia arcaica". "Utopia" não no sentido vulgar, de sonho impossível, mas no de algo que ainda não tem lugar. "Utopia arcaica" porque tem sua fonte num passado remoto. Uma das lugar. "Uto inspiraçós desta "utopia ar como personificação da saudade do lembrança do hetairado - é Antigona, evocadora de uma "lei mais antiga", matriarcado. Antígona é personagem evocadora de una "lesta utopia arcaica sim, uma "lei arcaica", a lei do matriarcado. O conteudo desta utopia arcaica sim, uma ê do feminismo seria a "utopia da ná cia , se dá como evocação ou saudade do matriarcado, de paz.

relacionado aos conteúdos de amor, união, paz: sonho de paz.

Ernst Bloch interpreta o ressurgimento do mito de Antígona no século $\mathrm{XX}$, como herança de uma eticidade anterior à da sociedade e do Estado patriarcais e sugere essa chave para ser explorada na compreensão do fenomeno histórico concreto do feminismo. Ou seja, se em Antígona se tematiza o dilehistórico concreto do para além do direito ma de uma ética fundada na no de com positivo, a mulher transgressora da lei da polis, promisso primitivo, com raiz no afeto, na cumplicidade de sangue e no vincuramiliar, evoca uma tradição "acima das tradições", menos no lo religioso familiar, everior, mas de anterior, que precede - no tempo? - a sentido de melhor, superior, mas de an anterior a tradição política. E o ideal desta lei para alén da lei, por tiás ou anterior a ela faria parte essencial do imaginário do movimento feminista de nosso tem ela, faria parte essencia tese a ser demonstrada, há aí uma sugestão para pesquisa e po. (Se não
reflexão.)

É muito problemático falar-se de matriarcado, como de um período hisE muito problemático falar-se de matriar mesa-redonda a tórico efetivamente existente. Como acaba de lembrar na ciência antropológica comunicação de Miriam Grossi, das atuais convicços da na gênese da famúlia panão se pode contar com a existência do matriarcado na genese dala dentro da triarcal, conforme as teses de Bachofen e Engels. Bloch ainda fala dentro da tradição de Engels e Bachofen. Todavia, embora se interprete a evocação do tradiça de Engels a uma dimensão da psichè humana antes de um tempo an-

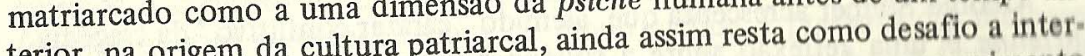
terior, na origem da cultura patriarcal, ainda assim resta como ressurgimento pretação do feminismo como utopia de não-violencia e como outro, o feminismo e o mito de Antígona, como utopias da superação da violência.

Quando Antígona diz: "Não nasci para partilhar o ódio ; nasci para par Quando Antígona diz: "Na nemia da não-violência a que se refore Emst tilhar o amor", se resume figur Bloch. É também por esta frase, talvez, que Hegel a podia consido-violéneli precursora, antecipadora do Cristo, onde se entear de tradiç̃o judaico-eriatî.

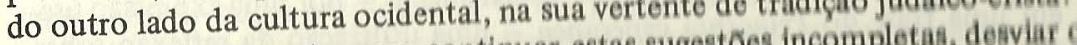

Seria interessante, para continuar estas sugestoes incompletas, desviar foco de luz sobre a figura da outra mulher presente na mesma obfa de soto cles. Já se tem escrito muito sobre Antigona. Ja la tem esorto mate abo di

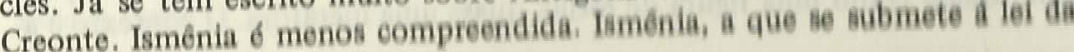

cidade, à lei do Estado, da sociedade, dos deuses diurnos, dos deuses olímpicos, da razão, da vida. (Tem-se notícias de que Ismênia viveu vida longa...) A mulher covarde, atingida pela ação alheia, a tragédia alheia. Embora possa ter sobrevivido à Antígona, na peça ou na vida real, Ismênia é aquela que ficou à sombra, que não ganhou o papel-título, que não entrou na história, que merece talvez ser melhor iluminada e analisada.

Uma última sugestão que trago para este Seminário é a de que, na esteira da hipótese de Ernst Bloch sobre a ressurreição do mito de Antígona no seio, na alma da rebelião das mulheres no século XX, as pesquisadoras - as que sei presentes nesta sala - busquem dialogar com a obra de autoras nosias sob a luz desta hipótese. Parece-me possível ver o universo de valores "an tigonais" na aspiração ao heroismo de personagens de Tânia Faillace - tambem presente nesta sala neste momento. Como também posso pressentir como "antigonais" a força do compromisso com os mortos e dos laços de famílii no mundo dos romances de Lya Luft.

"Não nasci para partilhar o ódio. Nasci para partilhar o amor." É um tisco querer resumir Antígona. Mas se ela devesse ser resumida, essa frase a relumiria. Resta saber se esta frase também pode resumir a alma do feminis180 modemo, essa que aparece na obra literária das mulheres de nosso tempo. (1) 0 que eu tinha a dizer.)

\section{REFERENCIAS BIBLIOGRÁFICAS}

II OCH, Iunest, Le Principle espérance. Paris, Gallimard, 1982, t. II, p. 180-1. ioNNA IX, Andró. Civilisation grecque: d'Antigone à Socrate. Lausanne, La Guilde du Iive, 1954

iii iI G.W.E, La phénoménologie de l'esprit. Trad. Jean Hypollite. Paris, Aubie Manteime, 1941

IACAN, Jaeques. Le Séminaire - Livre VII: L'éthique de la psychanalyse. Paris, Seuil,

II I Ah, Jean-Luc. Trois léctures d'Antigone. In: Antigone - tragédie de Sofocle. Camange, de l'Aire, 1981

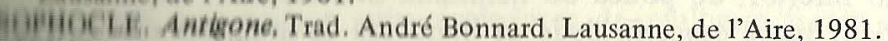

IIII I Georese Les Antigones. Paris, Gallimard, 1986.

11 . 1 , lan Plerre \& VIDAL-Naquet, Pierre. Mythe et tragédie en Gréce ancienne. Finti, Trangeis Maspero, 1982. 